\title{
Stimulus correlates of the discrimination behavior of children '
}

DONALD R. BROWN AND JEANNE A. GOLDSTEIN

PURDUE UNIVERSITY

The discrimination performance of 5 and 6 year old children was tested using 80 three-choice oddity problems. Using random polygons as patterns, a $U$-shaped function was found between discrimination latency and number of independent sides. Significant effects between problems within each sided ness level suggest that $S$ s discriminate on the basis of specific pattern attributes as well as information content.

This study is one in a program designed to contribute to the development of a psychophysics of visual form perception. The general problems have been discussed elsewhere (Attneave \& Arnoult, 1956; Brown \& Owen, 1967; Michels \& Zusne, 1965). Previous studies have demonstrated that visual discrimination performance of tree squirrels (Michels et al, 1962), raccoons (Hitchcock et al, 1963), monkeys (Polidora, 1966), and adult humans (Brown et al, 1962; Owen \& Brown, 1966) may be systematically related to quantified pattern characteristics. This study attempts to extend these results to children.

Random polygons, generated by Method 1 of Attneave \& Arnoult (1956), were randomly selected from a sample of 1000 to construct 20 , three choice oddity problems at each of four levels of sidedness $(4,8$, 12, and 16 independent sides). Problems were constructed by randomly pairing two polygons with the same number of sides, randomly designating one the "correct" pattern, and repeating the incorrect pattern to form the three choice problem. All patterns were equated in area at $12.5 \mathrm{sq}$ in. and photographed as black figures on a white background. The stimulus domain from which these patterns were sampled has been described in detail by Brown \& Owen (1967). Method

Twenty-one Ss between the ages of 5 and 6 years were tested one trial on each of the 80 problems. Sequence and order effects were controlled by using a 4 by 4 Latin square for sidedness and randomly assigning problem sequences within each sidedness level. Ss were tested individually in an apparatus which displayed the problems, dispensed an M\&M candy for correct responses, and recorded latency. The $S$ was instructed that on each trial one pattern was different and was a "good guy," two others were alike and were "bad guys," and that he should pick out the good guy by pressing on him. On each trial, when a guillotine screen was raised the display was illuminated and the timer started. When $S$ responded, the Illumination was extinguished, the timer stopped, and an $M \& M$ was delivered for correct responses. Testing was preceded by practice on a square-diamond problem and was conducted in a dimly lighted room in a $2 \mathrm{~h}$ session.

\section{Results and Discussion}

Since errors were negligible, an analysis of variance was computed on latency scores under the assumption that sidedness was a fixed variable and Ss and problems were random variables. The test for the sidedness main effect used a quasi-F statistic (Winer, 1962, p. 199) and was signiflcant $\left(F^{\prime}=18.13\right.$, df $=3 / 93, p<.001$ ). In addition, the problem effect was tested at each sidedness level and was significant in each case $(p<.01)$.

Mean discrimination latency as a function of sidedness is plotted in Fig. 1. A trend analysis indicated that both the linear and quadratic components of this function were significant $(p<.01)$. This finding is in accord with previous results with a variety of species. The curvilinear relation has been interpreted to mean that the processing of patterned stimuli involves an interaction between discriminability (pattern information utilizable under a given set of experimental conditions) and actual information content of the stimuli (Brown et al, 1962). Very simple patterns (e.g.,

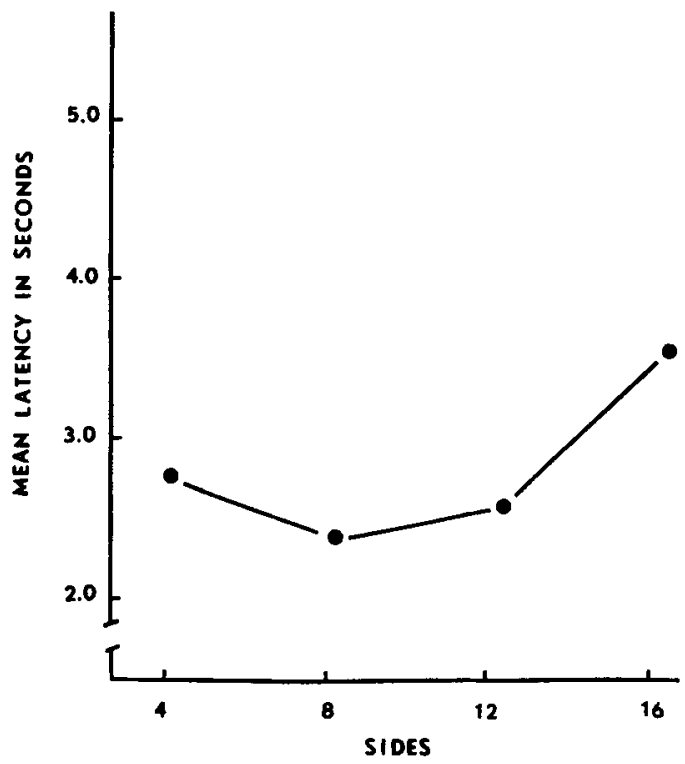

Fig. 1. Mean response latency as a function of sidedness levels. Data are for $21 \mathrm{Ss}$ and 20 problems at each sidedness level. 
4 sided polygons) are less free to be unique and are, therefore, difficult to discriminate even though the information available may be quickly processed. As complexity increases, patterns are more free to vary and discrimination is correspondingly easier. However, beyond some optimal level of complexity (herein, 8 sided figures) accurate discrimination becomes more difficult, suggesting that the figures contain more information than can be optimally processed. It is tempting to relate these data to those reported for preferences (Munsinger, Kessen, \& Kessen, 1964). However, most such studies suffer from lack of generality due to limited sampling of stimuli.

The significant problem effects within each sidedness level also support previous findings and have two important implications for further research. The first is simply that the temptation to use small samples of patterns should be avoided since performance is in part problem or pattern specific. The second is that any quantification system must go beyond specifying information content since performance varies within, as well as between, information levels. Recent psychophysical (Sternberg, 1966) and physiological data (e.g., Lettvin, Maturana, Pitts, \& McCullock, 1959) support the conclusion that pattern perception involves the extraction of specific pattern features. Although a quantification system sensitive to such pattern features is available for this stimulus domain (Brown \& Owen, 1967), it was not applied to these data due to limited sampling of patterns.

\section{References}

ATTNEAVE, F., \& ARNOULT, M. D. The quantitative study of shape and pattern perception. Psychol, Bull, 1956, 53, 452-471.

BROWN, D. R., HITCHCOCK, L., Jr., \& MICHELS, K. M. Quantitative studies in form perception: An evaluation of the role of selected stimulus parameters in the visual discrimination performance of human subjects. Percept. mot. Skills, 1962, 14, 519-529.

BROWN, D. R., \& OWEN, D. H. The metrics of visual form: methodological dyspepsia. Psychol, Bull., in press.

HITCHCOCK, L., Jr., MICHELS, K. M., \& BROWN, D. R. Discrimination learning: squirrels vs raccoons. Percept. mot. Skills, 1963, 16, 405-414.

LETTVIN, J. Y., MATURANA, H. R., PITTS, W. H., \& McCULLOCK W. S. What the frog's eye tells the frog's brain. Proc. Inst. Radio. Engrs, 1959, 47, 1940-1951.

MICHELS, K. M., PITTMAN, G. G., HITCHCOCK, L., Jr., \& BROWN, D. R. Visual discrimination: Three squirrels and quantified stimulus dimensions. Percept. mot. Skills, 1962, 15, 443-450.

MICHELS, K. M., \& ZUSNE, L. Metrics of visual form. Psychol. Bulh, $1965,63,74-86$

MUNSINGER, H., KESSEN, W., \& KESSEN, MARION L. Age and uncertainty: Developmental variations in preference for variability. $J$. exp. child Psychol, 1964, 1-15.

OWEN, D. H., \& BROWN, D. R. Physical correlates of pattern perception for the visual and tactual modalities. Paper read at the meeting of the Amer. Psychol. Assoc., New York, September, 1966.

POLIDORA, V. J. Stimulus correlates of visual pattern discrimination by monkeys: multidimensional analyses. Percept. \& Psychophys, 1966, $1,405-414$.

STERNBERG, S. Two operations in character recognition: some evidence from reaction-time measurements. Percept. \& Psychophys, $1967,2,45-53$.

WINER, B. J. Statistical principles in experimental design. New York: McGraw-Hill, 1962.

Note

1. This research was supported by Research Grant HD-00909 from the National Institute of Child Health and Human Development. 